\title{
Una perspectiva urbana de la pandemia en Panamá
}

José Antonio De Gracia

Arquitecto y Mgstr. en Diseño Urbano

Email: joseadgg@gmail.com

Recibido: 25 julio $2020 \quad$ Evaluado: 30 agosto $2020 \quad$ Publicado: 1 octubre2020

\section{Resumen}

El siguiente ensayo busca resaltar los efectos que tiene la pandemia sobre la forma en la que habitamos y construimos las ciudades. Entendemos que antes del estallido de la crisis social-sanitaria de la COVID-19, como en muchos lugares de Latinoamérica, Panamá se encontraba en un momento en el que su modelo urbano, social y económico había entrado en una fase de agotamiento y ahora se escala a un nivel aún mayor. Con la pandemia se han revelado los efectos negativos de la dispersión urbana, segregación de las viviendas y desaparición del espacio público que ahora se convierten en un obstáculo para controlar la propagación del virus.

En primer lugar, analizamos la relación entre la pandemia y lo urbano; es decir, el vínculo entre la vida urbana, principalmente la de los grupos más afectados en periferias de la ciudad, con las nuevas dinámicas de la cotidaneidad en medio del complicado panorama que ahora enfrentamos. A esto sumamos unas reflexiones sobre el efecto de los la excesiva centralización en la forma de gobierno que ha dejado con poca capacidad de respuesta a muchas ciudad del mundo, incluida la ciudad de Panamá. 
Adicionalmente, entendemos que, en una sociedad que necesita mantener la distancia física en la calle, el área metropolitana de la ciudad de Panamá no está preparada para cumplir con esta tarea luego de décadas de políticas urbanas orientadas al vehículo privado. Las actuaciones de emergencia en el espacio público por parte de las oficinas municipales y juntas comunales panameñas han sido escazas o inexistentes. A pesar de esto, han surgido algunas iniciativas de urbanismo táctico tratando de responder a la pandemia, y las comparamos con otras intervenciones anteriores para entender si se han llevado como un proceso en donde el beneficio es realmente de las comunidades.

Además, debido a noticias recientes en su contra en algunos medios internacionales, abordamos la polémica de la densidad de las ciudades desde una perspectiva teórica y con datos actuales para entender su relación con la propagación del virus en Panamá. El resultado de la investigación sugiere que el problema no yace en la alta densidad, sino en el hacinamiento de las viviendas y en la falta de accesibilidad urbana en los barrios más apartados. Todo esto nace de la construcción de una ciudad en donde priman la segregación y las desigualdades territoriales. Así, la consolidación del espacio público y el acceso a mejores viviendas junto con el replanteamiento de la ciudad actual son objetivos que habrían servido para afrontar una pandemia que llega sin previo aviso.

Palabras clave: centro-periferia, COVID-19, densidad, desigualdad, espacio público, hacinamiento, proximidad, urbanismo táctico.

\section{Abstract}

The following essay seeks to highlight the effects of the pandemic on the way we inhabit and build cities. We understand that before the outbreak of the social-health crisis of COVID-19, as in many places in Latin America, Panama was at a time when its urban, social and economic model had entered a phase of exhaustion and is now escalating at an even higher level. The pandemic has revealed the negative effects of urban sprawl, segregation of housing and disappearance of public space that now become an obstacle to controlling the spread of the virus.

Firstly, we analyze the relationship between the pandemic and the urban society; that is, the link between urban life, mainly that of the groups most affected on the outskirts of the city, with the new dynamics of everyday life in the midst of the complicated panorama that we face now. To this we add a few considerations on the effect of excessive centralization on the form of government that has left many cities in the world, including Panama City, with little capacity for response.

Additionally, we understand that, in a society that needs to maintain physical distance on the street, the Panama City metropolitan area is not prepared to fulfill this task after decades of urban policies oriented towards the private vehicle. Emergency actions in public space by Panamanian municipal offices and local assemblies have been scarce or non-existent. Despite this, some initiatives of tactical urbanism have emerged trying to respond to the pandemic, and we compare them with other previous interventions to understand if they have been carried out as a process where the benefit is for the communities.

Furthermore, due to recent news against it in some international media, we address the controversy of 
the density of cities from a theoretical perspective and with current data to understand its relationship with the spread of the virus in Panama. The result of the research suggests that the problem does not lie in high density, but in the overcrowding of the houses and in the lack of urban accessibility in the most remote neighborhoods. All this is born from the construction of a city where segregation and territorial inequalities prevail. In this way, the consolidation of public space and access to better housing together with the redefinition of the current city are objectives that would have served to confront a pandemic that arrives without warning.

Keywords: center-periphery, COVID-19, density, inequality, public space, overcrowding, proximity, tactical urbanism.

\section{Resum}

Aquest assaig busca ressaltar els efectes que té la pandèmia sobre la forma en què habitem i construïm les ciutats. Entenem que abans de l'esclat de la crisi social-sanitària de la COVID-19, com en molts llocs de Llatinoamèrica, Panamà es trobava en un moment en què el seu model urbà, social i econòmic havia entrat en una fase d'esgotament i ara es escala a un nivell encara més gran. Amb la pandèmia s'han revelat els efectes negatius de la dispersió urbana, segregació dels habitatges i desaparició de l'espai públic que ara es converteixen en un obstacle per controlar la propagació de virus.

En primer lloc, analitzem la relació entre la pandèmia i l'urbà; és a dir, el vincle entre la vida urbana, principalment la dels grups més afectats en perifèries de la ciutat, amb les noves dinàmiques de la quotidianitat enmig de I'complicat panorama que ara enfrontem. A això sumem unes reflexions sobre l'efecte dels l'excessiva centralització en la forma de govern que ha deixat amb poca capacitat de resposta a moltes ciutat de l'món, inclosa la ciutat de Panamà.

Addicionalment, entenem que, en una societat que necessita mantenir la distància física al carrer, l'àrea metropolitana de la ciutat de Panamà no està preparada per complir amb aquesta tasca després de dècades de polítiques urbanes orientades a el vehicle privat. Les actuacions d'emergència en l'espai públic per part de les oficines municipals i juntes comunals panamenyes han estat escazas o inexistents. Tot i això, han sorgit algunes iniciatives d'urbanisme tàctic tractant de respondre a la pandèmia, i les comparem amb altres intervencions anteriors per entendre si s'han portat com un procés on el benefici és realment de les comunitats.

A més, a causa de notícies recents en contra en alguns mitjans internacionals, abordem la polèmica de la densitat de les ciutats des d'una perspectiva teòrica i amb dades actuals per entendre la seva relació amb la propagació de virus a Panamà. El resultat de la investigació suggereix que el problema no rau en l'alta densitat, sinó en l'amuntegament dels habitatges i en la manca d'accessibilitat urbana als barris més apartats. Tot això neix de la construcció d'una ciutat en on primen la segregació i les desigualtats territorials. Així, la consolidació de l'espai públic i l'accés a millors habitatges juntament amb el replantejament de la ciutat actual són objectius que haurien servit per afrontar una pandèmia que arriba sense previ avís.

Paraules clau: centre-perifèria, COVID-19, densitat, desigualtat, espai públic, amuntegament, proximitat, urbanisme tàctic 


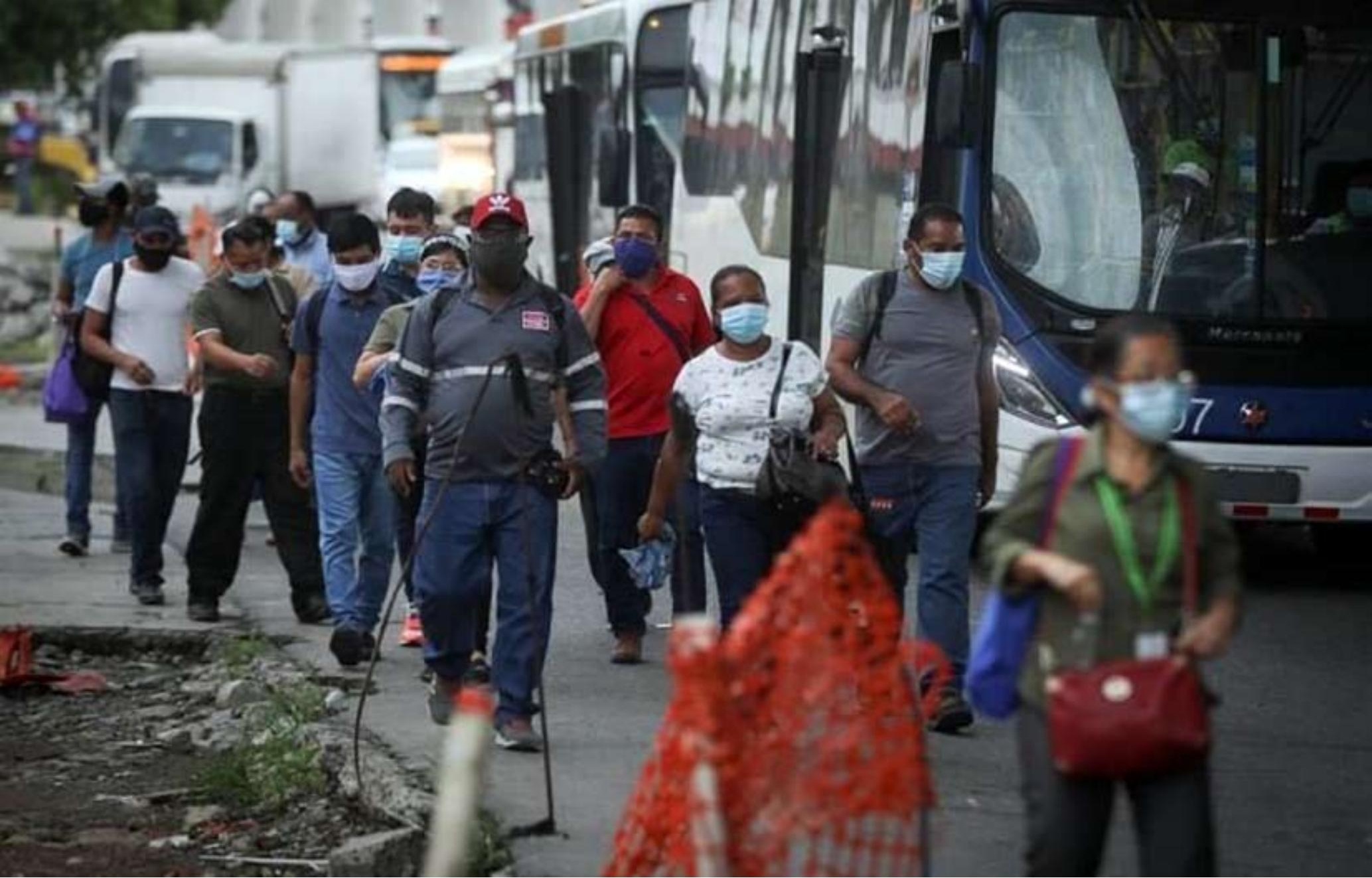

Imagen 1. Deterioro del espacio público en la ciudad de Panamá. Fuente: diario El Siglo.

\section{Introducción}

Panamá, al ser un país pequeño que supera apenas los 4 millones de habitantes, no ha sido noticia internacional por su cantidad de casos de COVID-19. Sin embargo, las cifras de infecciones y muertes proporcionales al número total de habitantes ubica a Panamá cerca de los primeros lugares y como uno de los países con el peor manejo de la crisis en el mundo. Los datos de la Organización Mundial de la Salud hacia finales de julio de 2020 indican que otros países en la región, con una gestión cuestionable de la pandemia, muestran números proporcionales similares a Panamá. Por ejemplo, Brasil con 43,57 muertes por cada 100 mil habitantes o México con 36,45 muertes por cada 100 mil habitantes no se ubican muy lejos de Panamá que registra 32,94 muertes por cada 100 mil habitantes y el porcentaje de letalidad no parece disminuir.

La pandemia se ha encargado de acentuar los problemas sociales y económicos de Panamá. El estado actual del país es el resultado de las políticas impuestas por el gobierno panameño desde que entramos en el periodo democrático, luego de acabar la dictatura militar, tras la invasión de Estados Unidos en 1989. Esta crisis nos ha llevado a una fase de aceleración en el incremento de las desigualdades en un país que ya se encontraba entre los diez más desiguales del mundo y el tercero en la región. Además, nos encuentra frente a una situación global de crecimiento económico incierto, inequidad social persistente, degradación ambiental constante y deterioro institucional creciente (Castro, 2017). Desde el inicio de la cuarentena en Panamá ya veíamos gente quedándose sin trabajo, estudiantes incapaces de continuar con sus clases, familias desalojadas 
de sus viviendas por incapacidad de pagar la renta y la creación de un discurso de criminalización en torno a cualquiera que saliera de su casa así fuera para ver cómo podía ganarse la vida en medio de este panorama. En fin, si no era evidente antes, ahora nos topamos de frente con la realidad de que la actual forma en la que organizamos nuestra vida no es sostenible, no pone por delante el bienestar de las personas ni garantiza sus derechos básicos.

"Ante la bancarrota cultural y moral del neoliberalismo, la pandemia - como aspecto principal de la contradicción de fondo en esta coyuntura - abre paso a un momento político nuevo. Se trata del debate de las opciones de transformación a partir de los cambios generados por la pandemia como problema social de salud, y como detonante de todos los problemas larvados por una economía que ha entrado en la que quizás sea la peor crisis de su historia" (Castro, 2020).

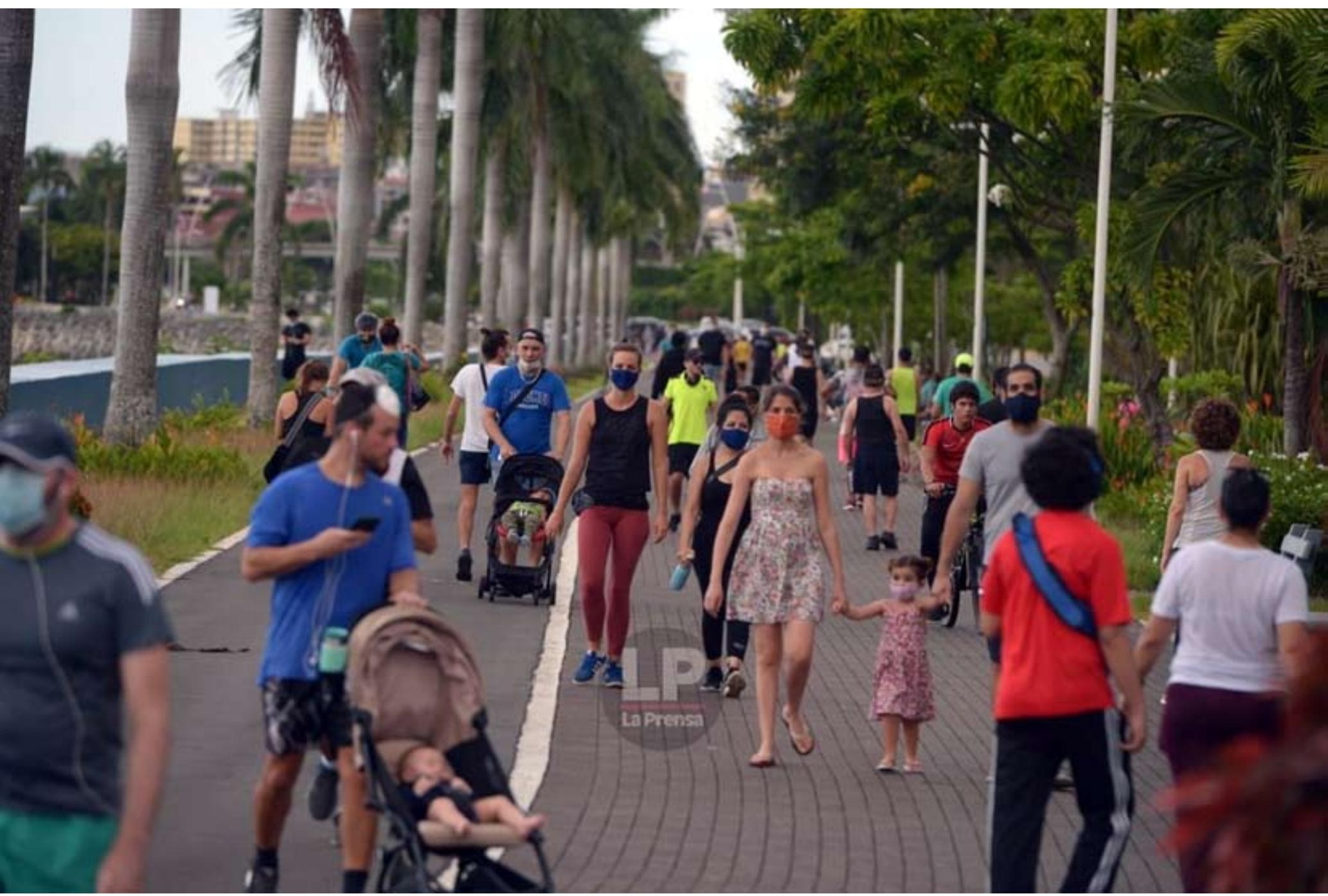

Imagen 2. Aglomeración en la Cinta Costera. Fuente: diario La Prensa. 


\section{La pandemia y lo urbano}

El presidente de la República de Panamá declaró una cuarentena total el 24 de marzo de 2020. Esta medida fue levantada momentáneamente a inicios de junio, luego de 68 días de confinamiento, y no duró más de una semana antes de que el gobierno central decretara nuevamente una cuarentena. El suceso se dio incluso en el contexto de un incremento de casos de COVID-19 en el país. Más que parte de un plan de reapertura, pareció una medida para apaciguar la reacción de las personas que exigían algún tipo de ayuda social, que en la mayoría de los casos era insuficiente y en otros inexistente. Ahora sí podrían salir a trabajar y a respirar, pero ¿cómo llegan a los lugares de trabajo, y dónde exactamente pueden detenerse a respirar? Chocamos nuevamente con otra realidad que ya estaba ahí antes: el deterioro y la ausencia de espacio público en el área metropolitana del distrito de Panamá y su relación con las dinámicas del trabajo, del ocio y del habitar la ciudad (Lefebvre, 1968).

El problema en su raíz vino con el distanciamiento en la calle. Pero el distanciamiento en sí no es el problema, sino la falta de espacio para poder distanciarse. $Y$ no solo la falta de espacio en lugares específicos, sino la ausencia de lugares específicos en la ciudad que puedan acoger a una población que necesita mantenerse a dos metros de distancia los unos de los otros. Siguiendo la narrativa del gobierno, los medios se encargaron de construir un pensamiento que dejaba las responsabilidades del cuidado colectivo enteramente en cada individuo. De esta forma, al hacerse virales imágenes de aglomeraciones de personas en marquesinas de autobús o en lugares como la Cinta Costera, el ruido mediático se enfocó en aquellos que decidieron aglomerarse voluntariamente. Sin embargo, ¿es realmente su culpa?

En el siglo XIX, cuando aún no se hablaba de la calle como espacio público, la expansión de las ciudades más allá de sus murallas se basó en resolver problemas como la higiene. La vida en los recintos amurallados era insalubre a causa del hacinamiento de las viviendas y la estrechez de la mayoría de las vías. Por esto, algunos ingenieros y urbanistas de este tiempo ya mencionaban la importancia de contar con suficiente espacio urbano libre para el ocio y otras actividades. Por ejemplo, Cerdá (1859) mencionaba que cada manzana debía tener como mínimo una superficie de área verde igual a la edificada en el nuevo ensanche de la ciudad de Barcelona. En cambio, en la ciudad de Panamá son pocos los espacios urbanos abiertos. Además del Parque Omar (único parque urbano de la ciudad) y la Cinta Costera (que en realidad dedica más del $90 \%$ de su espacio a usos destinados al vehículo privado), no existen lugares de uso público capaces de absorber de manera efectiva la intensidad de ocupación peatonal en la ciudad. Se les dio la opción a las personas de salir a la calle (otros tuvieron que hacerlo por necesidad), pero las aceras, los parques, las plazas, los lugares de espera, de intercambio y de movimiento eran los mismos que antes de la pandemia: insuficientes en su cantidad y pobres en su condición material. Las reformas del espacio público no formaron parte de la nueva normalidad.

La pandemia encontró mal paradas a muchas ciudades del mundo, sobre todo a aquellas que no habían dado prioridad a políticas urbanas y de vivienda apegadas a las necesidades específicas de 


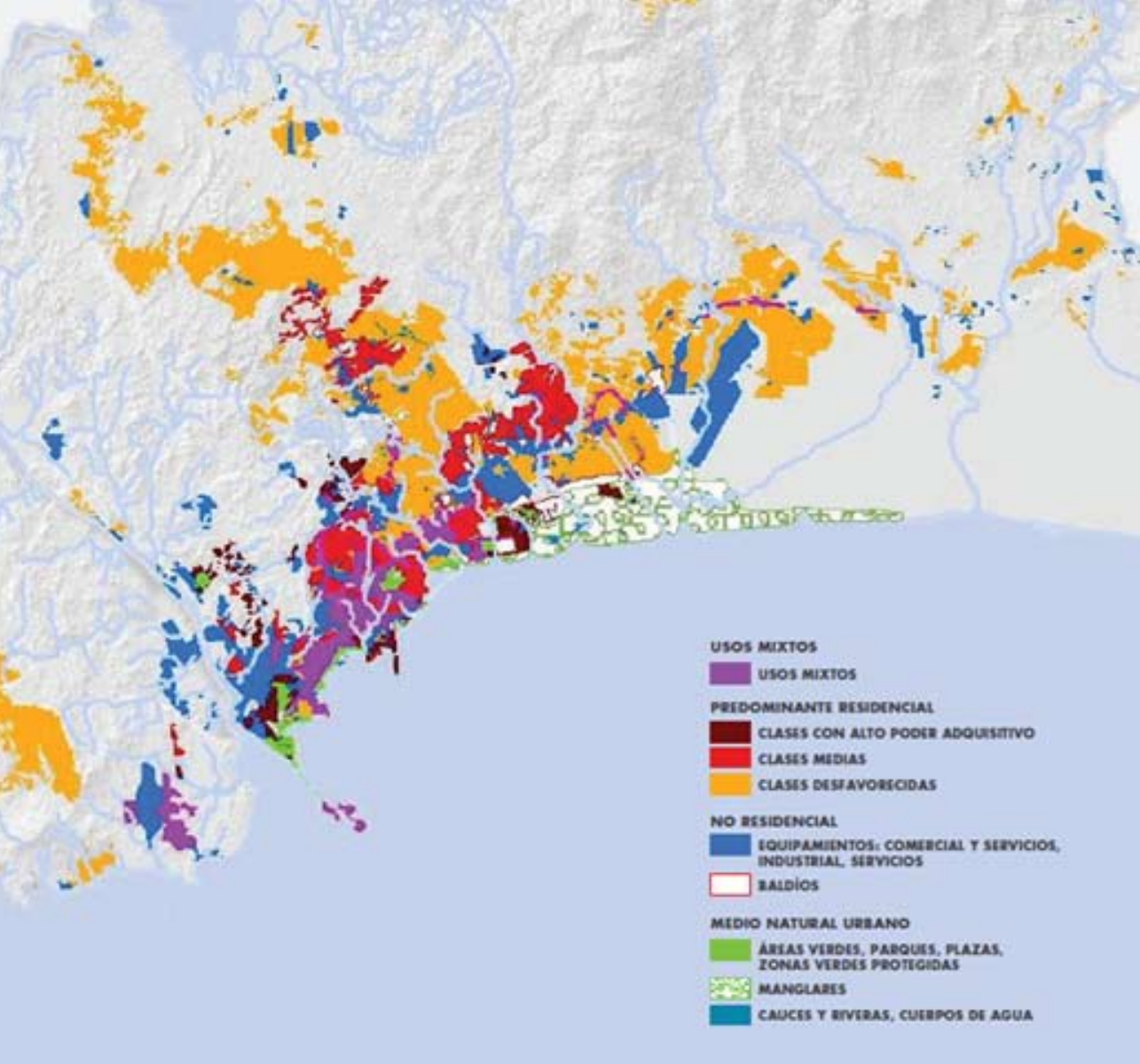

Imagen 3. Ausencia de áreas verdes, parques y plazas en el área metropolitana de la ciudad de Panamá. Fuente: Municipio de Panamá.

su población. ¿Cómo se comparan con Panamá? La ciudad de Londres, por ejemplo, cuenta con una periferia en condiciones similares a la de ciudad de Panamá: dispersa, con algunas viviendas en estado de hacinamiento y en circunstancias que se pueden considerar insalubres. La diferencia, que marca una ventaja para Londres comparada con ciudad de Panamá, es que la ciudad inglesa ya contaba desde antes de la pandemia con una amplia red de parques y espacios abiertos accesibles a una buena parte de su población. Otro punto de comparación es el alcance de las medidas de precaución que se tomaron durante los inicios de la pandemia en donde las dos ciudades experimentaron un manejo exclusivo desde sus gobiernos centrales. Es decir, tanto en Panamá como en el Reino Unido, la mayoría de las medidas de emergencia fueron homogeneas en todo el territorio nacional debido a los sistemas particularmente centralizados (Rode, 2020). Esta forma de organización política tiende a dificultar la respuesta de los actores locales. Los datos parecen indicar que en otras ciudades con mayor autonomía se han observado respuestas con resultados más favorables que nacen desde iniciativas regionales y que han permitido a las comunidades tomar medidas dependiendo de sus condiciones específicas. Este tipo de descentralización ha servido como una barrera mitigadora incluso en países con posturas negacionistas como Estados Unidos (Fernández de Losada, 2020).

La Ley de Descentralización panameña, que promueve una governanza de múltiples niveles y empodera a los ciudadanos, fue aprobada en junio de 2009. Sin embargo, sus beneficios no han sido aplicados por completo, salvo alguna excepción, y el estado se ha mantenido bastante centralizado hasta el presente: 
“Este prisma [del papel de la ciudadanía a través de la descentralización] se canaliza con las Juntas de Desarrollo Local, donde los ciudadanos se relacionan dentro de sus corregimientos por medio de la participación activa para tener decisión en todo lo relacionado a la organización, coordinación, planificación y ejecución del desarrollo integral de sus comunidades. Son muy pocos los corregimientos que han emprendido esta herramienta de participación en el distrito de Panamá; sin embargo, hay luces de distintas comunidades que se están organizando para tal fin. [...] Sumado a lo anterior, no solo se nutre la vinculación del ciudadano en las decisiones municipales, también estas asociaciones podrían coadyuvar en momentos de crisis como la que estamos viviendo, beneficiando no solo a los residentes de determinado corregimiento, sino también a los demás" (Fong, 2020).

Las intervenciones en el espacio urbano de las ciudades del mundo tampoco tardaron en aparecer. En algunos lugares la respuesta de los gobiernos locales ha sido recurrir al urbanismo táctico como herramienta fundamental de nuevas políticas urbanas ante la crisis. Esta estrategia ha sido capaz de brindar resultados rápidos frente a la necesidad de incrementar los espacios peatonales en la ciudad y facilitar el distanciamiento físico. Ha sido tan fácil como restarle espacio al vehículo privado con el uso de pintura y conos de tráfico para sumarlo a otros tipos de itinerarios. En Buenos Aires, por ejemplo, han peatonalizado o redistribuido el espacio urbano en unas 100 calles y avenidas de la ciudad (Lanfranchi, 2020). En París se está dando un proceso de conversión en el que inicialmente 50 kilómetros de carriles reservados para autos, que van paralelos a las líneas de metro más concurridas, pasan a ser carriles para bicicletas como forma de limitar el uso excesivo del vehículo privado mientras el transporte público se mantiene en baja capacidad por ser espacios con mayor riesgo de infección (Henry, 2020). Este tipo de acciones han proporcionado resultados rápidos a costos relativamente bajos. Aunque, si bien estas intervenciones funcionan para salvar el momento, el urbanismo táctico por sí solo está lejos de convertirse en la solución ideal como política urbana ante la pandemia: "[...] no se puede pensar que parchando los distintos déficits de la ciudad se solucionarán los problemas" (Sánchez, 2018). La apuesta, ya mismo, debería ser por inversiones a largo plazo en el espacio público.

Hasta el momento, las autoridades municipales de la ciudad de Panamá no han realizado intervenciones de urbanismo táctico para facilitar el distanciamiento físico. La única acción de este tipo se ha llevado a cabo en las esquinas de dos manzanas de Santa Ana, el antiguo arrabal del centro histórico de la ciudad, y lleva el nombre de La Parada Sana. Con el proyecto se ampliaron dos aceras en colaboración con artistas a través de pintura en el suelo y se adecuó una marquesina de autobús. La iniciativa se da por parte de la organización Huertos Urbanos y la compañía de bienes raíces Conservatorio S.A. que está llevando a cabo un desarrollo inmobiliario junto a la intervención y en otras partes del barrio. No obstante, sin restarle valor al breve alivio que puede traer el proyecto, al ser una operación que no responde a una política urbana concreta, aún no está claro si esto representa un tipo de acción que nace desde abajo con verdadera participación de la comunidad o si solo se trata de una operación de marketing urbano de la compañía inmobiliaria tras los sucesos de la COVID-19. Incluso más sospechosa fue la iniciativa iPlanta por Santa Ana!, 


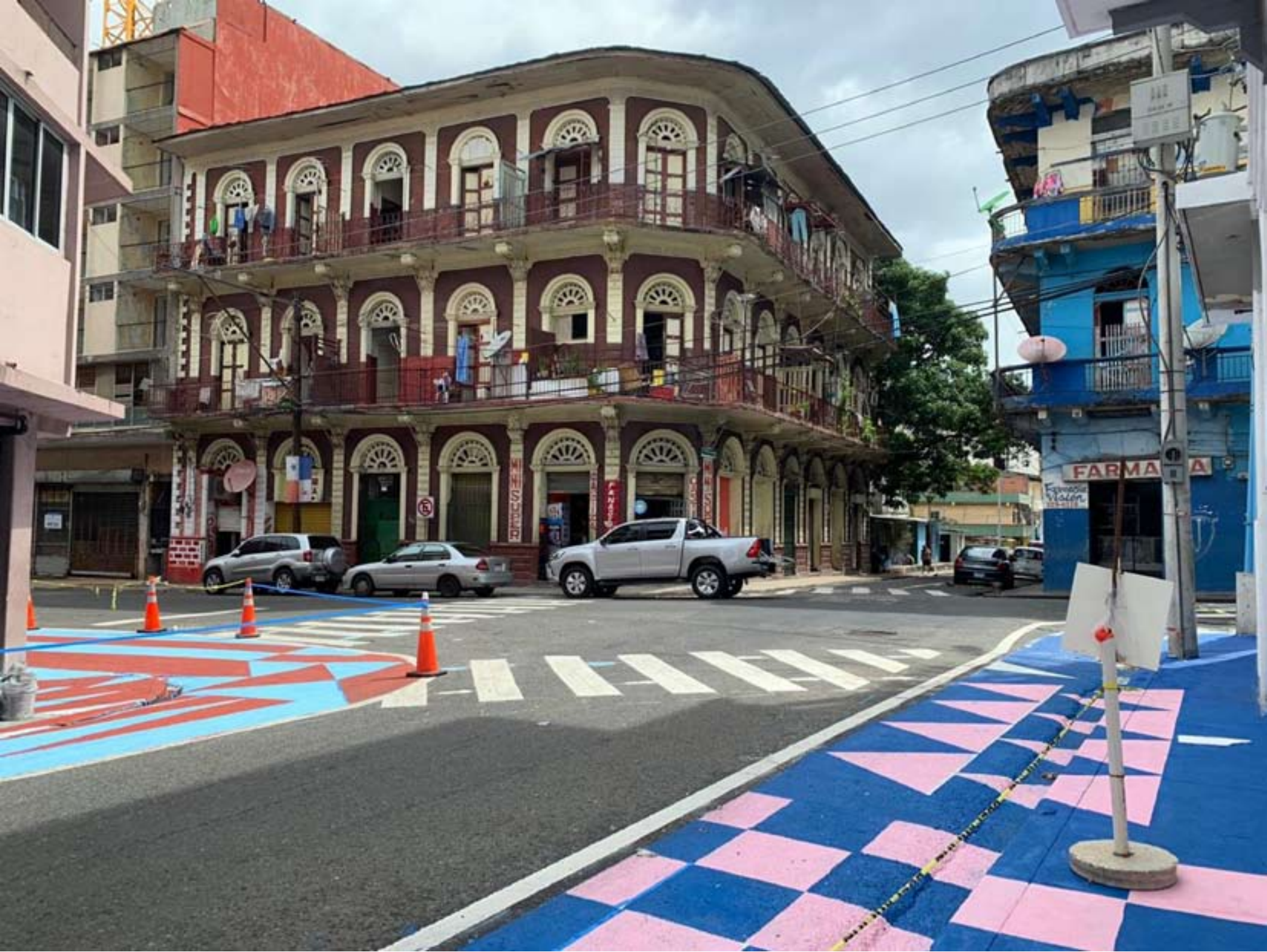

Imagen 4. Intervención artística de urbanismo táctico en Santa Ana durante la pandemia. Fuente: Benito De Gracia.

también organizada por Huertos Urbanos durante la pandemia, que animaba a los vecinos de Santa Ana a sembrar plantas por su cuenta para embellecer el barrio y premiaba con comida a quienes participaban.

Es necesario entender que la función primordial de estos ejercicios es servir como herramienta comunitaria para evidenciar un problema. Es decir, llamar la atención por medio de intervenciones rápidas en el espacio público que solucionen temporalmente los asuntos que cierta comunidad considere necesarios. Así, eventualmente los gobiernos locales pueden materializar operaciones urbanas reales basadas en esto. ¿Cómo se compara esta operación con otros proyectos anteriores de urbanismo táctico en Panamá? En el 2019, el Municipio de Panamá en conjunto con el Banco Interamericano de Desarrollo (BID) llevaron a cabo el proyecto de urbanismo táctico Panamá Camina: comparte la Central. La intervención planteaba peatonalizar parte de las calles adyacentes a la Plaza 5 de Mayo, también en Santa Ana, con el uso de pintura, arte y mobiliario temporal para pacificar el lugar que era dominado por el vehículo privado y que constituye una de las entradas a la Avenida Central: la principal calle peatonal en la ciudad donde abunda el comercio y el movimiento de personas. Los resultados posteriores indicaron que el 85\% de las personas mostró preferencia por mantener la peatonalización de forma permanente (Gaitán, 2019), lo que ya parecía evidente 


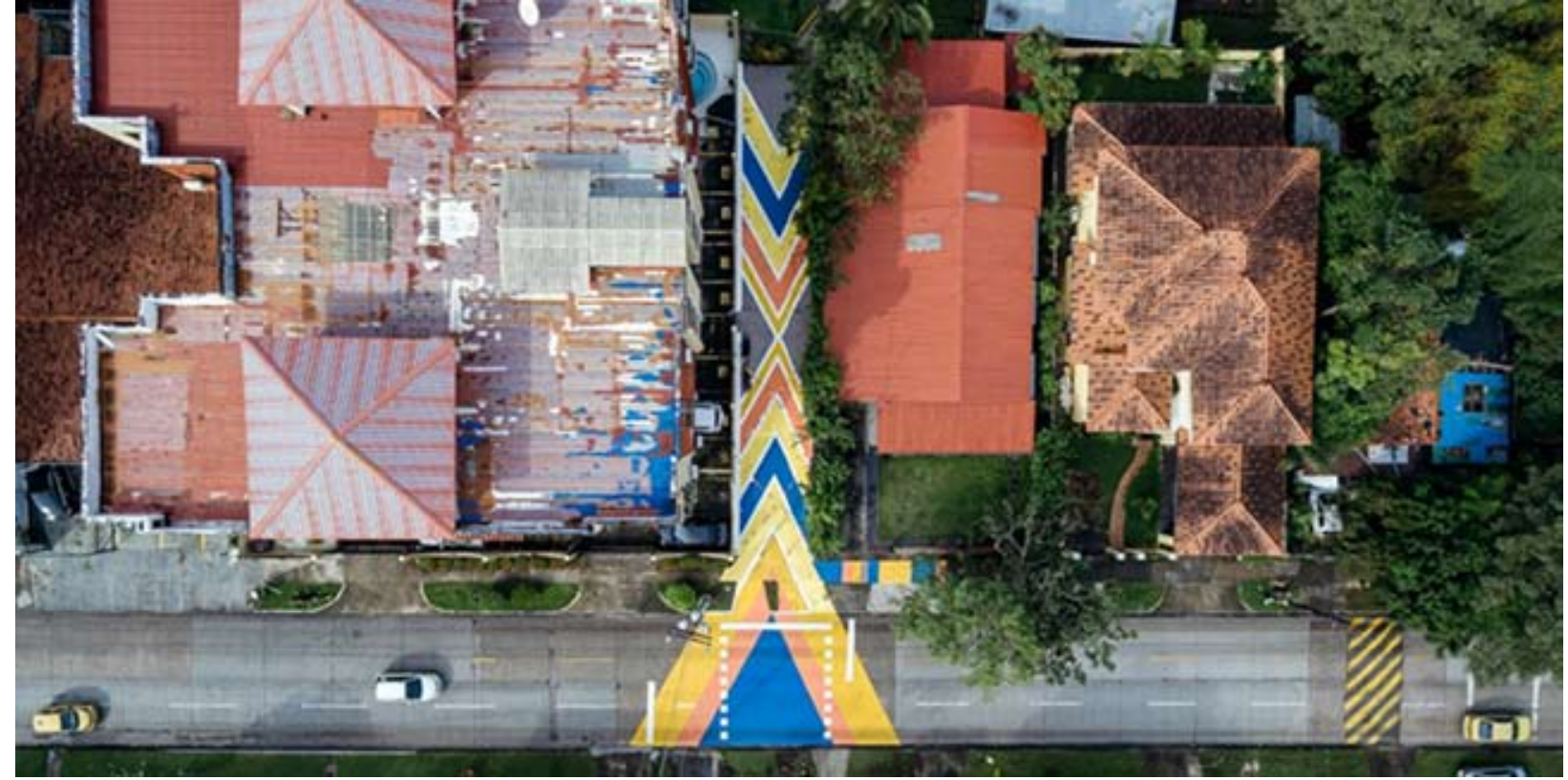

Imagen 5. Calle Victoria. Intervención de urbanismo táctico en el barrio de Miraflores, 2019. Fuente: Giro urbano.

por la excesiva ocupación peatonal que el sitio experimentaba por años. Ahora, si entendemos el urbanismo táctico como herramienta ciudadana para evidenciar un problema, no queda claro por qué el Municipio de Panamá necesitaba demostrarse a sí mismo o a la ciudadanía la necesidad de ampliar el espacio peatonal en la Plaza 5 de Mayo. Más aún si recordamos que en 2017 la misma administración municipal ya había realizado restauraciones y reformas a la plaza. Si el problema ya era evidente, ¿por qué no fue resuelto de forma permanente con esa intervención?

Otro proyecto de urbanismo táctico que vale la pena mencionar es La Victoria (2019) ubicado en el barrio de Miraflores en el corregimiento de Betania. La intervención es llevada a cabo por el estudio de espacio público Giro Urbano en conjunto con la Asociación Pro-Mejoras de Miraflores, la cual está constituida por los vecinos del barrio. Miraflores fue construido inicialmente en 1948 como un proyecto de vivienda para la clase media en lo que una vez fue la periferia de la ciudad. Hoy, la periferia se ha desplazado por la expansión urbana y el barrio ha quedado ubicado en una zona central. La calle Victoria, que constituye la principal vía de articulación en la zona, conecta una estación de la Línea 1 del Metro de Panamá que fue inaugurada en 2014 con una futura expansión de la Línea 2 que será construida en los próximos años. Recientemente, la circulación peatonal y vehicular ha aumentado debido a la tensión entre estos dos nodos, así como la velocidad de los autos y la contaminación ambiental y acústica. Un comunicado de la asociación de vecinos señala que ya se habían manifestado antes sobre cómo el aumento del tráfico estaba afectando negativamente la calidad de vida en el barrio. La calle comenzó a adquirir las propiedades de una carretera y se volvió más insegura. Además, en la calle Victoria se ubica una de las entradas al parque Carlos A. Delvalle: el principal espacio comunitario del barrio. Entendiendo lo anterior, la organización en conjunto con los vecinos decide actuar sobre la pacificación de la calle mientras mejoran el acceso al parque que se encontraba en malas condiciones. Así, con el uso de pintura se resalta un cruce peatonal y se enmarca la entrada al parque. El proyecto adquiere sentido, también, porque se ubica dentro de las estrategias que se proponen con la construcción de la Línea 1 del metro a través del Plan Integral de Movilidad Urbana (PIMUS), en donde se recomienda el desarrollo de calles completas; esto es, integrales y con usos mixtos, de las zonas de influencia directa a las estaciones del metro. De esta forma, se resuelve parcialmente un problema y se 
evidencia la necesidad de mejores condiciones de circulación para los vecinos y las personas que caminan en el lugar.

Entre los ejemplos enunciados, La Victoria parece ser el único que nace como un proceso verdaderamente local que abre las puertas a una intervención futura permanente, y cuyos intereses y beneficios no son más que los de los propios vecinos. Con respecto a Panamá Camina: comparte la Central, al no materializarse la propuesta con un proyecto definitivo de diseño urbano, puede haberse tratado de un problema presupuestal que no permitió incluir la peatonalización completa de las calles en la intervención original del municipio. Otra posibilidad es que el urbanismo táctico, por su carácter efímero, haya sido aplicado para responder de forma moderada a un problema que era evidente con el fin causar menos controversia en la esfera pública de una ciudad dominada por el vehículo privado. Por último, en La Parada Sana parece que el urbanismo táctico se utiliza como una herramienta de gentrificación disfrazada de ayuda para los vecinos de Santa Ana bajo el supuesto de promover el distanciamiento físico, en donde el beneficio a largo plazo es principalmente de los desarrollos inmobiliarios. No sería la primera vez que el arte en el espacio urbano es utilizado para poner de moda un lugar estigmatizado y así eventualmente poder expulsar a sus residentes de bajos ingresos (Pascual Esteve, 2018). Al momento de esta publicación, hay indicios de que la organización planea expandir el área de intervención en Santa Ana.

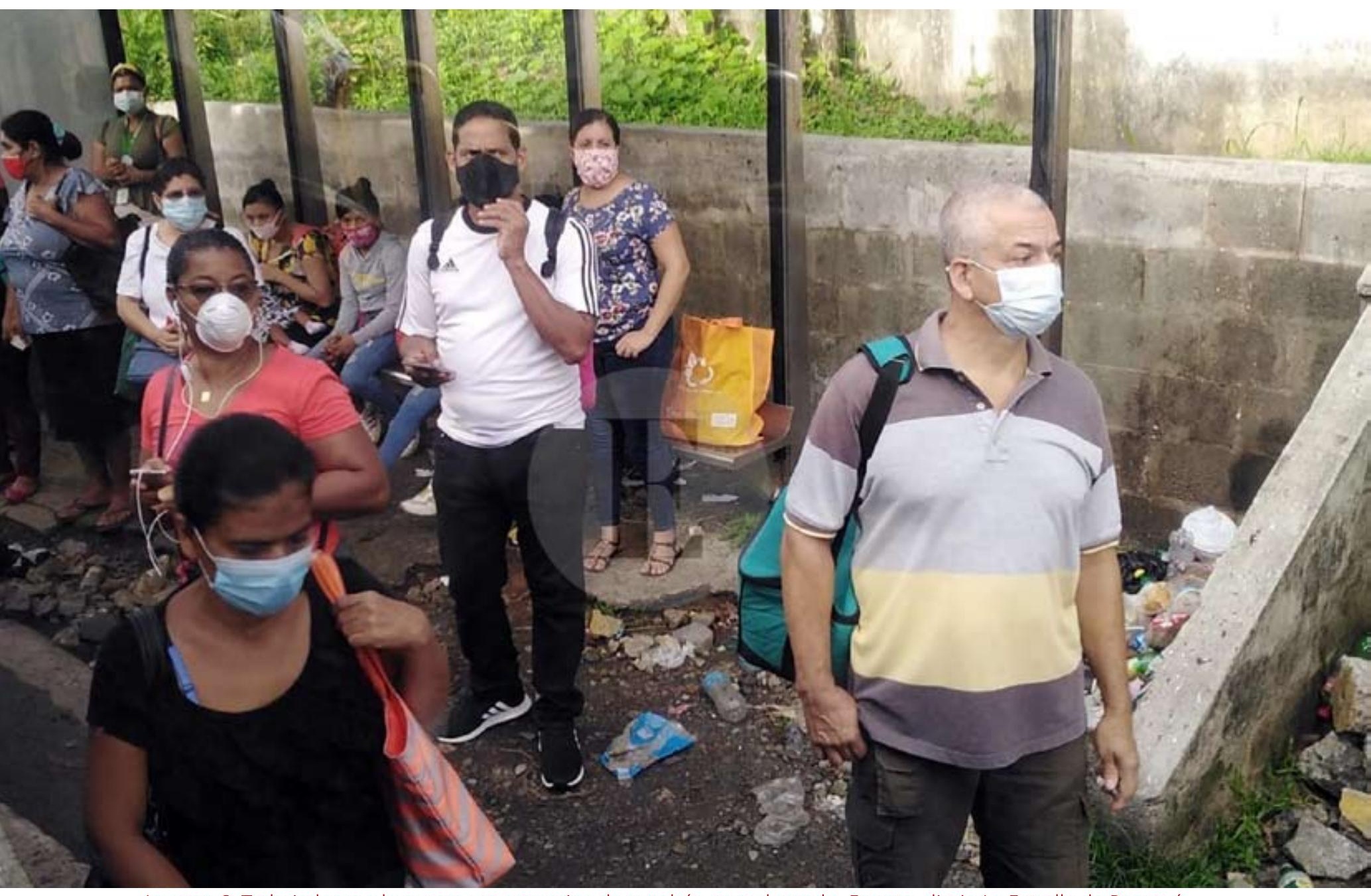

Imagen 6. Trabajadores a la espera y marquesina de autobús en mal estado. Fuente: diario La Estrella de Panamá. 


\section{Transporte, informalidad y pobreza}

En cuando al transporte, solo el 39\% de las familias en la provincia de Panamá cuentan con un vehículo según un estudio del BID y el Municipio de Panamá en 2015. El resto, mayormente la clase trabajadora sometida a la territorialidad de las desigualdades sociales y económicas, ha tenido que desplazarse a pie y transporte público hacia sus trabajos y demás lugares de actividad que condicionan su movilidad cotidiana (Miralles, 1999). Gran parte de esta población reside en las periferias, donde el sistema de transporte se ha demostrado insuficiente y el acceso a servicios es limitado. Nos encontramos en un momento en el que el transporte público pierde atractivo por su incapacidad de promover ambientes que faciliten el distanciamiento físico. A raíz de esto, las autoridades han reducido la capacidad de ocupación del Metro de Panamá a un 40\%. Las paradas de bus, reducidas y en malas condiciones en su mayoría, han servido como plataforma para aglomeraciones de personas que se dirigen hacia sus lugares trabajo. Y allá donde la red de buses no llega o la frecuencia es baja, los busitos piratas llenaron ese vacío. Muchas veces con poca regulación en cuanto al distanciamiento entre viajeros. Un informe del Instituto Nacional de Estadística y Censo (INEC) en 2018 indicaba que la tasa de empleo informal en Panamá llegaba al $44 \%$. Esto significa que la pandemia encontró a casi la mitad de los trabajadores y trabajadoras sin ningún tipo de afiliación a la seguridad social y en riesgo de perder sus ingresos. Así, con tanta incertidumbre para estas personas, mantener la distancia y no subirse a un bus que está lleno puede significar no llegar a su trabajo. En medio de este panorama es necesario recordar que estas prácticas informales e inseguras nacen de una o varias necesidades que no están cubiertas.

Conforme a los datos del Ministerio de Economía y Finanzas, en el 2015 el 23\% de la población en Panamá se encontraba en condición de pobreza y el 10\% en pobreza extrema. No es casualidad que los mayores focos de infección se encuentran en barrios pobres y periféricos de la ciudad. De acuerdo a los datos oficiales del Ministerio de Salud de la última semana de julio de 2020, los cinco corregimientos con mayor cantidad de personas infectadas por el coronavirus son: Tocumen (2457 casos, 15\% de pobreza), Arraiján Cabecera (2350 casos, 8\% de pobreza), 24 de Diciembre (2121 casos, 20\% de pobreza), Pacora (2121 casos, 26\% de pobreza) y Belisario Porras (1942 casos, $22 \%$ de pobreza). Todos estos forman parte de la periferia en donde el hacinamiento en los hogares (mayor posibilidad de contacto con infectados), la poca ventilación, el difícil acceso a bienes y servicios, la represión policial constante (uso de gases lacrimógenos) y el espacio público en pésimas condiciones (falta de espacio y vegetación como purificadora del aire) son también la causa de enfermedades respiratorias que se vuelven más peligrosas en el contexto de la pandemia del coronavirus.

Un caso singular es el del corregimiento de Calidonia que se ubica en el centro de la ciudad con pocos casos de COVID-19 comparado con los anteriores y con un índice de pobreza que no supera el $5 \%$. A pesar de esto, el corregimiento era el tercero con la tasa de transmisión real del virus (RT) más alta del país a principios de junio, solo detrás de Santiago y Pacora. Las razones pueden ser varias. Los medios han señalado como principal motivo los casos en los que habitan más de dos 
familias en una sola vivienda, pero también podemos suponer que otro factor importante es la presencia y el incremento del comercio informal en el lugar. A través de un censo del Municipio de Panamá en 2019, se ubicaron a más de 400 comerciantes informales en el corregimiento de Calidonia donde los espacios urbanos abiertos son escasos y esenciales para este tipo de actividad. De esta manera, la práctica de una economía informal que se desarrolla en la calle, estructura básica del espacio público, se vuelve muy peligrosa en medio de una pandemia. Al final, los más vulnerables han sido los más expuestos al virus.

Imagen 7. Plano de espacios abiertos en el corregimiento de Calidonia. Fuente: Municipio de Panamá.

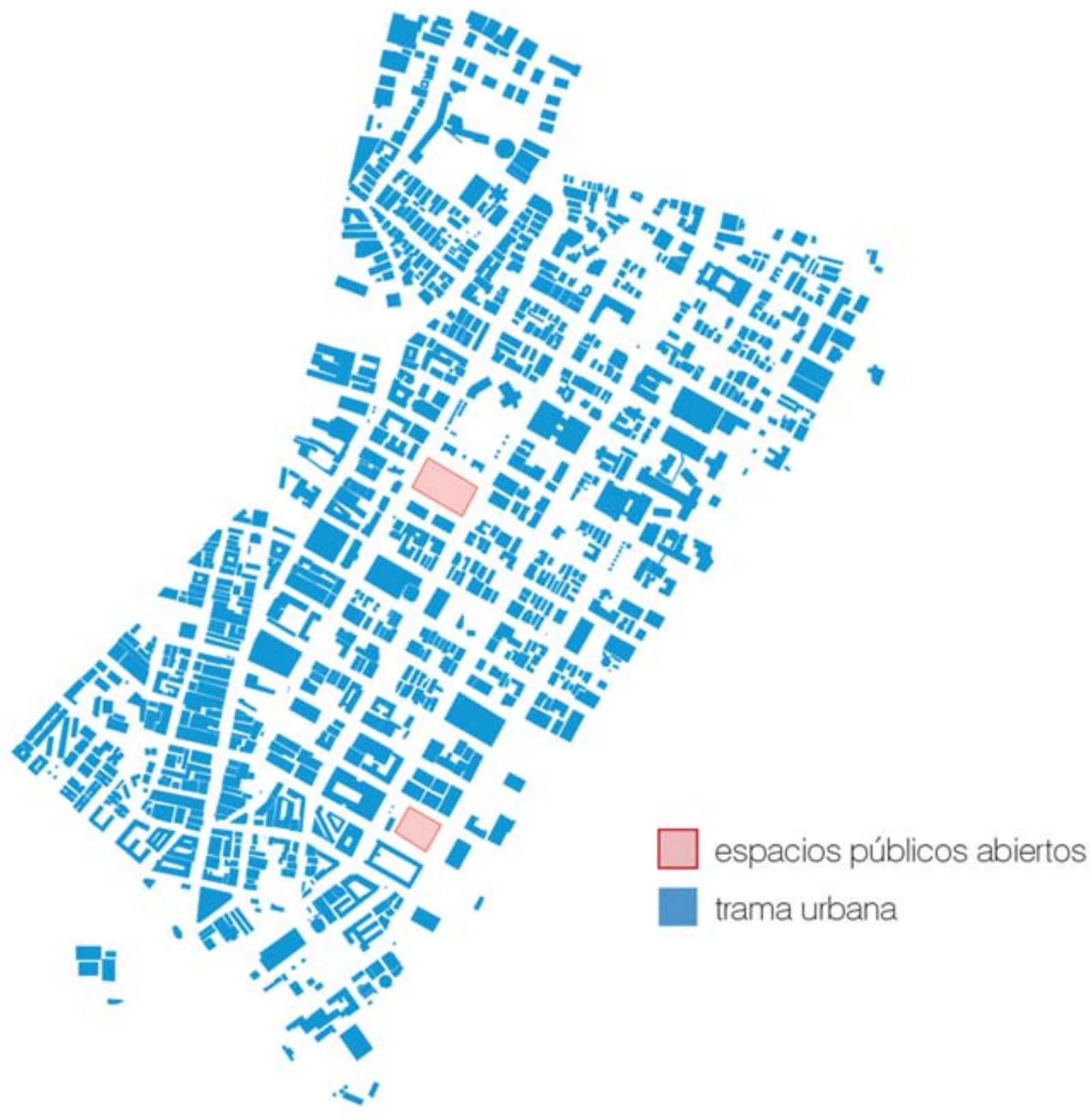

Densidad, hacinamiento y COVID-19

Sabemos que más de la mitad de la población mundial vive en ciudades. En el caso específico de Latinoamérica, esa cifra sobrepasa el 80\%, y Panamá se mantiene cerca de la media con un 75\% de 
sus habitantes ubicados ciudades, principalmente en el área metropolitana de la ciudad de Panamá. La COVID-19 es en esencia una pandemia urbana (Parnell \& Mazetti, 2020). Es de esperarse que la mayoría de los casos positivos se estén dando en ciudades del mundo con alta conectividad. Sin embargo, como ya hemos señalado en el caso de Panamá, al mirar bien dónde están las mayores concentraciones de infecciones por el virus dentro de cada ciudad, la distribución de los casos no es uniforme en todo el territorio urbano.

Durante el mes de marzo cuando el coronavirus iniciaba su expansión por América, solo el estado de Nueva York poseía la mitad de los casos positivos en todo Estados Unidos y el $6.5 \%$ de los casos totales del mundo. Durante una declaración ante los medios, el gobernador del estado expuso su hipótesis: la ciudad de Nueva York, con casi 9 millones de personas y una densidad de 10 mil habitantes por km2, era el entorno perfecto para la propagación del virus. Pero no es necesario irse demasiado lejos para escuchar este tipo discurso. Hace poco, en Panamá, varios médicos asesores del Ministerio de Salud también hablaban de la densidad como motivo de la propagación del virus. De esta manera, la alta densidad en las ciudades se comienza a plantear como un obstáculo para contener la pandemia. A primera vista parece lógico: los contagios se dan por contacto y una mayor densidad significa que en una zona determinada habrá mayor cantidad de personas. Entonces, ¿̇la densidad se convierte en enemiga de las ciudades en el contexto de una pandemia? ¿Debemos concentrarnos en construir ciudades con criterios suburbanos y de baja densidad?

Antes de satanizar la densidad y las ciudades compactas, primero es necesario revisar cuál es su utilidad. El beneficio de la densidad es, en primer lugar, el fomento de la proximidad como un valor urbano fundamental (Miralles \& Marquet, 2014). En otras palabras, la densidad; cuando es aplicada correctamente en el territorio, permite que más personas se ubiquen más cerca de los bienes y servicios que necesitan para vivir. Los desplazamientos en la movilidad cotidiana suelen ser más cortos y la accesibilidad urbana incrementa. En cambio, un modelo de baja densidad tiende a enfocarse en una única función que se olvida de otras actividades como el ocio, la protesta o la sociabilidad y se reduce al movimiento de personas y mercancías a una velocidad incrementada, ya que las distancias entre los distintos usos son mayores:

"En la organización funcional y en las bajas densidades la velocidad del peatón (4 km/h) no es apta para las necesidades de desplazamiento cotidianas. Las calles se adaptan al artefacto mecánico apropiado en estas circunstancias: el vehículo privado, y con él se incrementa la segregación y la selección del espacio público" (Miralles \& Cebollada i Frontera, 2003).

La densidad es también la que dicta los tipos de medio de transporte que predominan en un territorio determinado. Mientras que las bajas densidades favorecen el uso del vehículo privado (que solo está al alcance de una minoría en Panamá) como principal herramienta de movilidad, las densidades más altas aumentan la posibilidad de oferta y acceso al transporte público (Vuchic, 1999).

La densidad y la proximidad urbana juegan también un papel fundamental en la integración social. 

en los hogares cuando esta es excesiva. Según Toderian (2020), es posible tener una alta densidad sin hacinamiento, y también se puede tener hacinamiento sin alta densidad. Este es uno de los paradigmas en la relación del centro (alta densidad, poco hacinamiento) con la periferia (baja densidad, mayor hacinamiento).

Regresemos al caso de Nueva York. En un estudio realizado por la Association for Neighborhood \& Housing Development (ANHD), en donde se comparan los datos de densidad / hacinamiento / casos de COVID-19, los resultados apuntan en dirección opuesta a lo que indicaba el gobernador: en general, mientras más densos los barrios, menores son los casos positivos del virus. En cambio, se muestra una relación mayor entre acumulación de infecciones con los barrios de baja densidad donde el hacinamiento en los hogares y la pobreza es mayor. Los sucesos en otras ciudades también desmienten el argumento de que la densidad es perjudicial durante la pandemia. Algunos distritos de Hong Kong, con una densidad mucho más alta que la de Nueva York, no presentan una cantidad significativa de casos de COVID-19 (Ng, 2020). Esto indica que son otros factores los que impulsan la propagación del virus en áreas urbanas. Manhattan, una zona neoyorquina céntrica de alta densidad construida y con residentes en buenas condiciones económicas, no muestra una mayor concentración de personas infectadas por el virus. Por el contrario, las comunidades más afectadas, como Queens o el Bronx, se encuentran en zonas periféricas donde el tamaño de los apartamentos es menor y la cantidad de personas por vivienda incrementa (Walters, 2020). E estudio demuestra que la densidad no es responsable del alto nivel de contagios en Nueva York, sino la segregación y la inequidad dentro de la ciudad.

¿Cómo se compara Panamá con Nueva York? Desde hace varios años, la ciudad de Panamá ha mantenido un crecimiento descontrolado. Entre 1980 y 2015 la población del área metropolitana de la ciudad de Panamá se duplicó de 700 mil habitantes a 1.5 millones, mientras que; en ese mismo periodo de tiempo, su huella urbana aumentó en casi 4 veces su tamaño: de 10 mil a 37 mil hectáreas. Esta gran ocupación del espacio con una mínima implantación de usos produce una disminución en la densidad construida que se acentúa a medida que nos alejamos del centro. Como resultado, la densidad media del área metropolitana se mantiene baja en 5,400 habitantes por $\mathrm{km} 2$, un $40 \%$ del total de las viviendas se ubican en asentamientos informales y el $30 \%$ de las los hogares en las provincias de Panamá y Panamá Oeste se encuentran en estado de hacinamiento. De acuerdo a un estudio del Municipio de Panamá, un escenario óptimo de crecimiento sería alcanzar una densidad de 8,400 habitantes por km2 para el año 2050, pero la densidad en la ciudad se ha mantenido en un proceso de reducción desde la década de 1940 hasta el presente.

Como hemos mencionado, los lugares con gran cantidad de casos de COVID-19 se encuentran en la periferia del área metropolitana de la ciudad capital y la mayoría son zonas de baja densidad con índices de pobreza altos y un nivel de hacinamiento muy por encima del de las comunidades menos golpeadas por el virus. De los cinco corregimientos con mayor cantidad de casos en todo el país a finales de julio de 2020, cuatro de ellos muestran una densidad significativamente baja en comparación con la media del área metropolitana. 


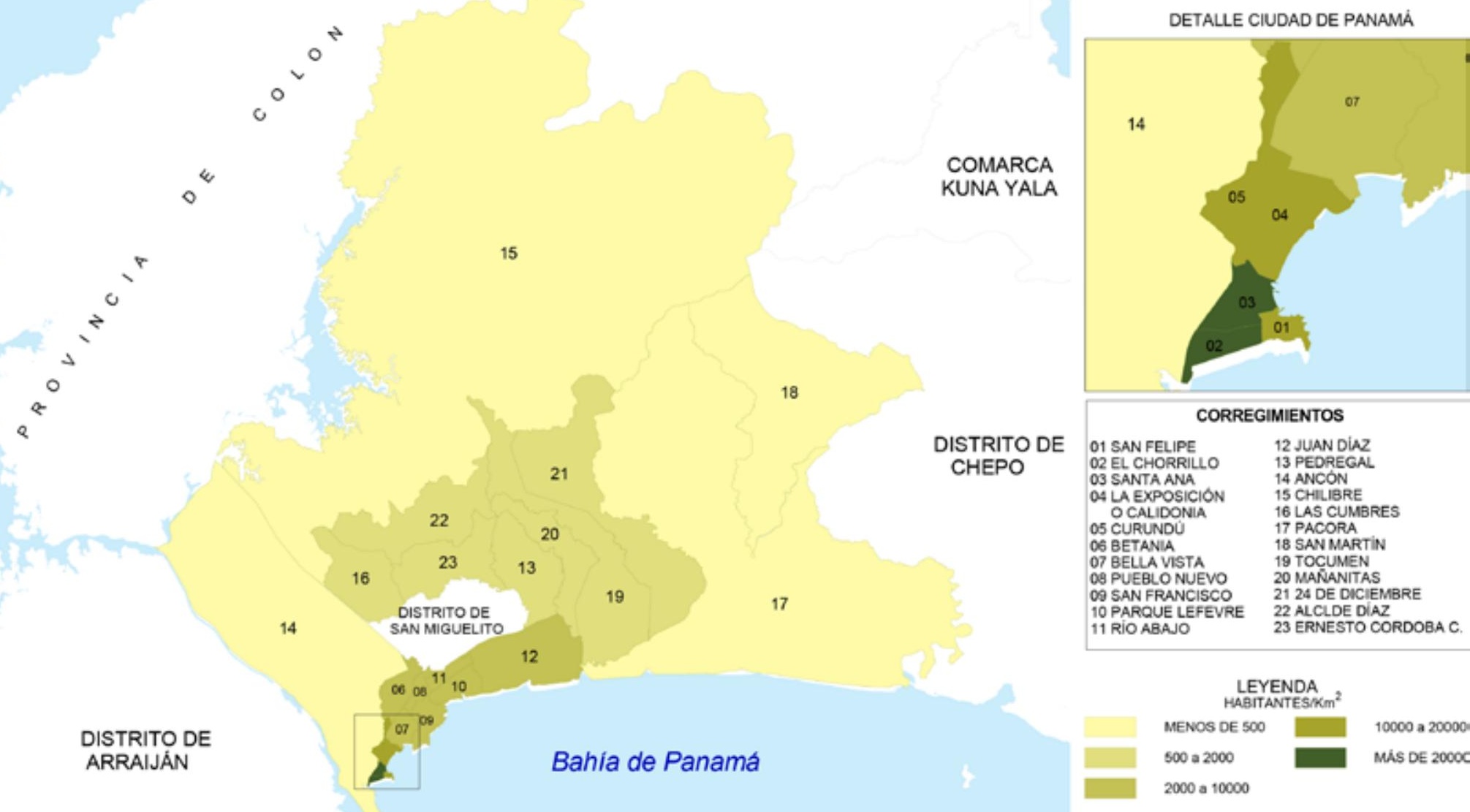

Imagen 10. Densidad por corregimiento en el distrito de Panamá. La densidad disminuye hacia la periferia mientras se encierra el distrito de San Miguelito. Fuente: Instituto Nacional de Estadística y Censo (INEC).

El caso particular de Belisario Porras, con una densidad bastante más alta, es motivo de estudio. Este corregimiento forma parte de San Miguelito: un distrito que se encontró atrapado en el crecimiento descontrolado de la ciudad de Panamá hacia el este. La pobreza y el hacinamiento también son problemas que se manifiestan en el corregimiento. Según noticias recientes, se han encontrado casos en los que habitan más de 15 o 20 personas en una sola vivienda. Esto demuestra la importancia de revisar primero aquellos problemas sociales o económicos y a examinar también si el entorno construido, a pesar de ser denso, cuenta con los rasgos que promueven la proximidad: usos de suelo mixtos que generen servicios y comercios cerca de las viviendas, la inclusión de parques y plazas en la trama urbana o la multifuncionalidad del espacio público. La alta densidad por sí sola no es garantía de mejor accesibilidad a bienes y servicios; sin embargo, para tener mejor accesibilidad urbana sí es necesario trabajar con barrios densos. Si los índices de pobreza y hacinamiento se mantienen elevados, la densidad por sí sola no resolverá todos los problemas.

Según Cabrera (2016), los desarrollos urbanos y de vivienda en Panamá están al servicio de los negocios especulativos y del mercado inmobiliario sin preocuparse por las consecuencias negativas sociales que pueden causar. Y agrega también que:

"No hay políticas de suelo urbano para impulsar el desarrollo de la vivienda social en buenas ubicaciones y en tramas integradas a la urbe. El gasto público dirigido a la vivienda de clase media es, más bien, un subsidio a las empresas que realizan proyectos inmobiliarios fragmentados en toda el área metropolitana, sin ninguna relación entre sí, generando un tejido difuso que aumenta la dispersión (en especial en La Chorrera y Arraiján) y obliga a 


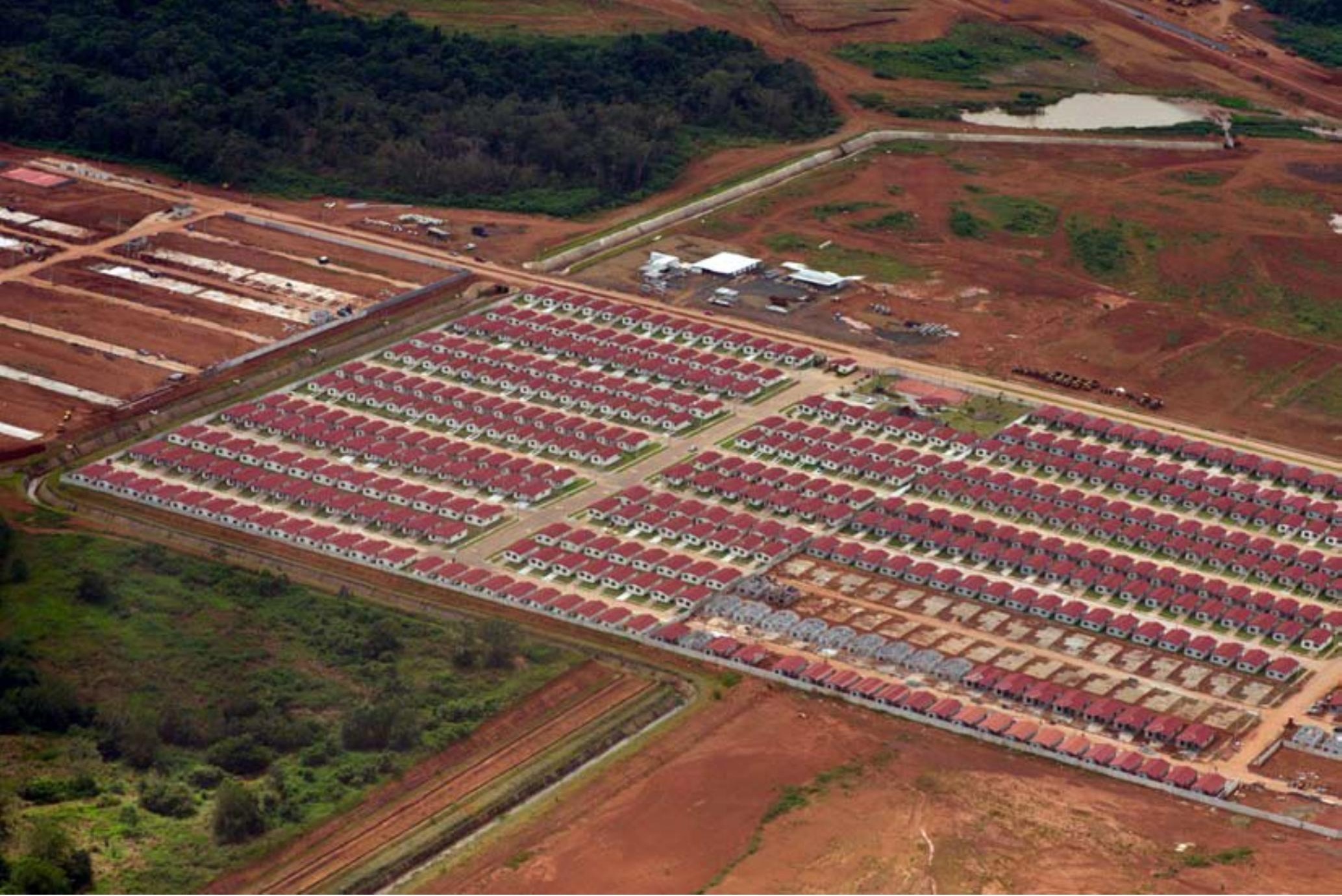

Imagen 11. Tipología de desarrollos inmobiliarios en la periferia de la ciudad de Panamá. Fuente: Luis Alfaro.

miles de personas a movilizarse a diario desde la periferia hacia los polos de empleo, en el casco urbano central, provocando congestiones cada vez peores y aumentando, además, la contaminación."

Teniendo en cuenta todo lo anterior, la densidad bien aplicada a través de un proceso más inclusivo de hacer ciudad puede ser beneficioso en el contexto de una pandemia por la proximidad a los servicios de salud, el ahorro del tiempo en asistencias de emergencia y la posibilidad de contar con acceso a los recursos necesarios a distancias caminables. Lo último resulta fundamental en el caso de Panamá ya que el tiempo para estar en la calle es limitado debido a la cuarentena que ha impuesto el gobierno (2 horas por día con días asignados para hombres y mujeres por separado). De hecho, reducir significativamente la densidad de las ciudades significaría provocar la emergencia de otros problemas que ya experimentan los barrios más apartados. La solución debe ser dignificar las periferias y aumentar el acceso a hogares de mejor calidad. Después de todo, una vivienda digna se traduce en mejores condiciones sanitarias para quienes la habitan. 


\section{Conclusiones}

Entonces, ¿cómo debemos avanzar? La pandemia de la COVID-19 pone a las ciudades (a su organización y capacidad de adaptación) en la primera línea para combatir los efectos de esta crisis social de salud. Zevi (2020) Ilama a realizar un replanteamiento del futuro de las ciudades y que ciertos problemas sean atendidos con urgencia. Entre ellos: repensar las dinámicas del trabajo y del ocio, reformar la infraestructura urbana para permitir el distanciamiento físico y proteger a las comunidades más vulnerables que han sido víctimas de la segregación social. Adicionalmente, podemos agregar que la transición hacia gobiernos más descentralizados, para otorgar mayor autonomía y facilitar la respuesta de los actores locales, debe estar en el centro de la discusión. Con esto, la centralidad multiple tiene que convertirse en una cualidad urbana inherente de las ciudades en nuestro tiempo. Cuando es así, cada lugar específico, del centro o la periferia, tiene mayor capacidad de desarrollar una administración más democrática, actividad económica local, servicios cercanos, espacio público de calidad, identidad propia, etc. y de esta forma mejorar la calidad de vida de sus habitantes. Hay dos cosas que tener en cuenta sobre la centralidad múltiple. Primero, es necesario ser cuidadoso con las políticas que se implementen para su fomento ya que, al igual que con la densificación, estas pueden suponer un aumento de la renta en las áreas de nueva centralidad. Y segundo, el proceso de creación de estas zonas debe hacerse ententiendo que, a pesar de que adquieran un carácter más individualizado y autónomo, siguen siendo parte de una realidad urbana más grande que conforma el todo en la ciudad:

"Esta estrategia de fomento no se basa en la ocupacion y el aprovechamiento directo de unos suelos vacantes, siguiendo unas directrices de caracter mercantil, ni pretende introducir usos terciarios en sectores urbanos indiferenciados para asi generar mayores rentas. La promoción de areas de nueva centralidad, segun el modelo propuesto, parte de una vision globalizada de una ciudad hecha por partes que estan caracterizadas morfologicamente de manera muy diferenciada. Sus rasgas especificos, que hay que mantener haciéndolos participar en una realidad urbana de mayor ambito, han de reconocer la existencia de unas infraestructuras viarias y sistemas generales a nivel metropolitano, cuya incidencia ha de valorarse en el momento de formular estas operaciones autonomas" (Barnada, 1987).

Una vez conseguida la capacidad de tener una governanza de múltiples niveles eficiente, los gobiernos locales deben trabajar en combatir la urgencia de recurrir al vehículo privado como principal medio para mantener la distancia. Las nuevas políticas deben apuntar a promover alternativas sostenibles como caminar o andar en bicicleta. Sin embargo, esta transformación no es posible sin la adecuada redistribución del espacio urbano a favor del peatón y la creación de barrios densos que integren usos mixtos para mantener los distintos servicios y puestos de trabajo cerca de las viviendas.

Esto es más importante cuando se tiene en cuenta que la mayoría de la población en Panamá no cuenta con suficientes recursos para comprar un auto. Mientras el transporte público no pueda ser utilizado en su capacidad total y dejemos que el vehículo privado adquiera más protagonismo 
del que tenía antes, estaríamos alejándonos del desarrollo de una ciudad más sostenible y equitativa.

En cuanto a la adaptación física del espacio urbano, los ejemplos de otras ciudades son claros y existen guías de acceso público para la adecuación de calles, interfaces, plazas y parques. Esto se puede apreciar en un informe del National Association of City Transportation Officials (NACTO), en donde indican la importancia y la manera de ampliar el espacio público para las personas a través de intervenciones rápidas que integren a las comunidades en el proceso. Sin embargo, aunque estas soluciones de emergencia con el urbanismo táctico han logrado en algunas ciudades la ampliación temporal del espacio peatonal, la reducción en la probabilidad de contagios y la pacificación de la calle, es imperativo transformar esta temporalidad en algo permanente para ayudar a combatir la crisis actual y las que puedan venir después. La ampliación de un espacio peatonal a través de un trazo de pintura en la calzada no durará el mismo tiempo ni tendrá el mismo efecto a largo plazo que una acera bien consolidada con todos sus elementos básicos de urbanización: pavimentos, vados, alcorques, bordillos, imbornales, etc. (Lecea, 2006).

La realidad es que la mayoría de los habitantes del área metropolitana de la ciudad de Panamá viven en zonas con poco acceso a espacios de uso público y distantes de sus lugares de trabajo. Esto fuerza a la gente a tener que moverse muy lejos de su vecindario para poder ir a un parque (aglomeraciones en los escasos lugares que existen) o al lugar donde vende su fuerza de trabajo (aglomeraciones en interfaces y medios de transporte). Con el fracaso de una ciudad fragmentada, creciente y desigual, pasamos también a un nuevo momento político en la lucha por la democratización del espacio público y la organización de los usos en la ciudad. La crisis del coronavirus ha actuado como detonante de todos estos problemas que eran ignorados y acentúa la necesidad de políticas urbanas y de vivienda que pongan por delante las verdaderas necesidades de la población.

Únicamente así podremos hacer uso pleno de todos los tiempos y espacios en la ciudad en el contexto de una pandemia y dejar atrás el modelo urbano actual que solo promueve la pobreza de la vida cotidiana para gran parte de la población. La cantidad de contagios por el virus sería diferente de haber contado con acceso a una vivienda digna y de haber construido el espacio público como un bien pensado para todos y todas. Después de todo, es imposible mantener la distancia donde no hay espacio para distanciarse.

En fin, el virus no se ha extendido tampoco porque las ciudades sean densas, sino porque el hacinamiento es una realidad para una parte vulnerable de la población que históricamente ha sido expulsada de la ciudad y su centro. Además, el hacinamiento también se traslada hacia afuera de la vivienda donde la calle pierde su función de encuentro y el espacio público desaparece: "Es en la calle donde tiene lugar el movimiento, de catálisis, sin los que no se da vida humana, sino separación y segregación, estipuladas e inmóviles. Cuando se han suprimido las calles [como lugar de encuentro] (desde Le Corbusier, en 'los barrios nuevos'), sus consecuencias no han tardado en manifestarse: desaparición de la vida, limitación de la 'ciudad' al papel de dormitorio, aberrante funcionalización de la existencia" (Lefebvre, 1972). 


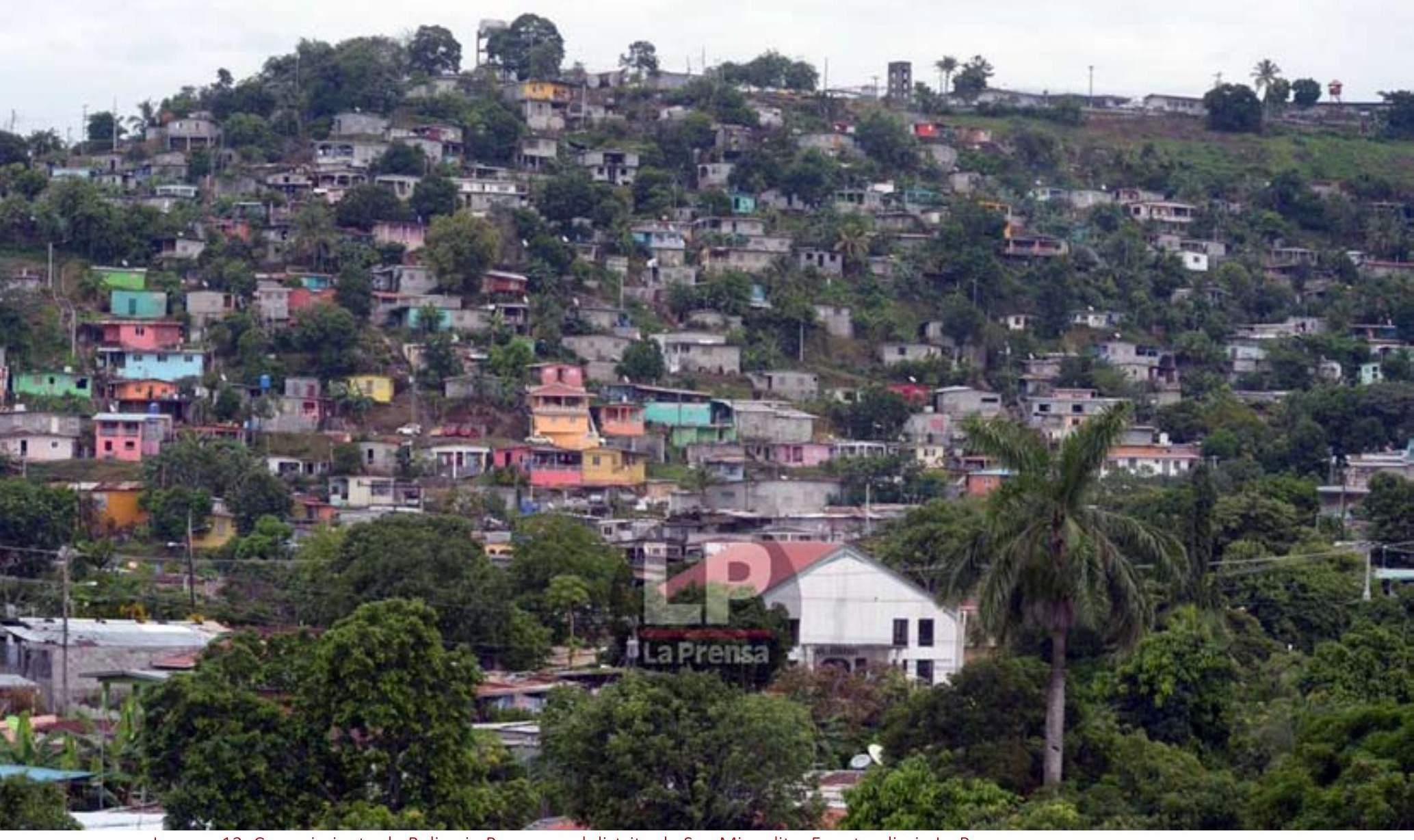

Imagen 12. Corregimiento de Belisario Porras en el distrito de San Miguelito. Fuente: diario La Prensa.

Los ejemplos de esto sobran: en las marquesinas de autobús repletas de trabajadores y trabajadoras, en las calles con poco espacio para la sociabilidad, en los corregimientos con insuficientes parques y plazas, en el único supermercado de un barrio que debe servir a un número incrementado de personas, en las viviendas donde residen más de dos familias o donde se hallan familias numerosas en espacios reducidos. Allí, donde prima la segregación, el motor de la propagación del virus ha sido la desigualdad y cómo se expresa en el territorio urbano que ocupamos. La densidad es un factor en la ecuación de hacer ciudad que puede apuntar a la mejora en la calidad de vida de las personas, pero los elementos negativos más influyentes han demostrado ser el hacinamiento, la pobreza y la construcción de una ciudad excluyente que ignora el bienestar de sus habitantes. 


\section{Bibliografía}

BARNADA, Jaume (Coord.) (1987). "Arees de nova centralitat". Barcelona: Ayuntamiento de Barcelona.

BID, MUPA (2015). Plan de acción Panamá metropolitana. Sostenible, humana, global. Disponible en: https://dpu. mupa.gob.pa/wp-content/uploads/2018/08/Plan-de-Accion-Panama-Metropolitana.compressed.pdf

BID, MUPA (2015). Panamá Urban Lab. Plan de renovación urbana para el corregimiento de Calidonia. Disponible en: https://dpu.mupa.gob.pa/wp-content/uploads/2017/06/INFORME URBAN-DESIGN-LAB CALIDONIA BID large.pdf

CABRERA, Magela (2016). Alto a la urbanización salvaje. Julio 15, 2016, de La Prensa. Disponible en: https://www. prensa.com/impresa/opinion/Alto-urbanizacion-Magela-Cabrera-Arias 0 4529547053.html

CASTRO, Guillermo (2017). Panamá en transición. Voces en el Fénix, 60, p. 109. Disponible en: www.vocesenelfenix. com/sites/default/files/pdf/12_13.pdf

CASTRO, Guillermo (2020). Panamá en pasado mañana. Abril 30, 2020, de NODAL. Disponible en: www.nodal. am/2020/04/panama-en-pasado-manana-por-guillermo-castro-h/

CERDÁ, Ildefonso (1859). Teoría de la Construcción de las Ciudades: Cerdá y Barcelona. Madrid: Instituto Nacional de la Administración Pública.

FARBER, Steven \& PÁEZ, Antonio (2011). Running to stay in place: the time-use implications of automobile oriented land-use and travel. Journal of Transport Geography, n. 19, p. 4.

FERNÁNDEZ DE LOSADA, Agustí (2020). "Managing a global pandemic. Towards more sustainable and resilient urban futures" en Agustí Fernández de Losada y Hannah Abdullah (Eds.), "Cities on the frontline: Managing the coronavirus crisis", Barcelona: Barcelona Centre for International Affairs.

FONG, Chiara (2020). "Pertenencia territorial”. Panamá: La Estrella de Panamá. Disponible en: https://www. laestrella.com.pa/opinion/columnistas/200729/pertenencia-territorial

GAITÁN, Nerys (2019). "El urbanismo táctico como herramienta de transformación ciudadana en Ciudad de Panamá", Huffpost. Disponible en: https://www.huffingtonpost.es/entry/el-urbanismo-tactico-como-herramientade-transformacion-ciudadana-en-ciudad-de-panama es 5de4b031e4b0913e6f8132a9

HENRY, Christine (2020). "Déconfinement à Paris: Anne Hidalgo veut faciliter les déplacements à vélo et à pied". París: Le Parisien. Disponible en: https://www.leparisien.fr/paris-75/deconfinement-a-paris-anne-hidalgo-veutfaciliter-les-deplacements-a-velo-et-a-pied-04-05-2020-8310735.php

INEC (2018). "Situación de la población ocupada". Panamá: Contraloría General. Disponible en: https://www.inec. gob.pa/archivos/P9141Comentarios\%20de\%20la\%20informalidad\%20A-2018-20-12.pdf

LANFRANCHI, Gabriel (2020). "Can COVID accelerate the metropolitan unity of Greater Buenos Aires?" en Agustí Fernández de Losada y Hannah Abdullah (Eds.), "Cities on the frontline: Managing the coronavirus crisis", Barcelona: Barcelona Centre for International Affairs.

LECEA, Ignasi de (2006). Sobre el proyecto del suelo. On the w@terfront, núm 8. Disponible en: www.raco.cat/index. php/Waterfront/article/view/217154

LEFEBVRE, Henri (1968). El derecho a la ciudad. Madrid: Capitán Swing Libros, S.L.

LEFEBVRE, Henri (1972). La Revolución Urbana. Madrid: Alianza Editorial.

MEF (2010). Atlas Social de Panamá. Hacinamiento en Panamá. Disponible en: https://www.inec.gob.pa/redpan/ sid/docs/documentos\%20tematicos/Atlas\%20social\%20de\%20Panama/14\%20-\%20Hacinamiento\%20en\%20 Panam\%C3\%A1.pdf

MEF (2017). Pobreza y desigualdad en Panamá. Disponible en: http://fapobservatorioods.com/wp-content/ uploads/2018/09/Pobreza-y-desigualdad-en-Panama-Mapas-a-nivel-de-Distritos-y-Corregimientos-2015.pdf

MIRALLES, Carmen (1999). "Modelos de movilidad en la Barcelona Contemporánea” en García Espuche, Albert y Salvador Rueda (Eds.), La ciudad sostenible, Barcelona: Centro de Cultura Contemporánea de Barcelona. 
MIRALLES, Carmen \& CEBOLLADA i Frontera, Ángel (2003). Movilidad y transporte. Opciones políticas para la ciudad. Junio 17, 2003, de Fundación Alternativas. Disponible en: https://www.fundacionalternativas.org/ laboratorio/documentos/documentos-de-trabajo/movilidad-y-transporte-opciones-politicas-para-la-ciudad

MIRALLES, Carmen \& MARQUET, Oriol (2014). La proximidad en Barcelona. Un análisis desde los tiempos de desplazamiento cotidianos. Revista Ciudades, n. 17, p. 99. Disponible en: https://iuu.uva.es/revista/listado-numeros/ ciudades-17/\#tab-id-1

MYRICK, Phil (2020). The recovery will happen in public space. Mayo 16, 2020, de Project for Public Spaces. Disponible en: www.pps.org/article/the-recovery-will-happen-in-public-space

NACTO (2020). Streets for pandemic response \& recovery. Disponible en: https://nacto.org/wp-content/ uploads/2020/06/NACTO_Streets-for-Pandemic-Response-and-Recovery_2020-05-26.pdf

NG, Mee Kam (2020). "Hong Kong's head start in tackling the new coronavirus" en Agustí Fernández de Losada y Hannah Abdullah (Eds.), "Cities on the frontline: Managing the coronavirus crisis", Barcelona: Barcelona Centre for International Affairs.

PARNELL, Susan \& MAZZETI, Clara (2020). "COVID-19 in Cape Town: initial state and civil society responses" en Agustí Fernández de Losada y Hannah Abdullah (Eds.), "Cities on the frontline: Managing the coronavirus crisis", Barcelona: Barcelona Centre for International Affairs.

PASCUAL ESTEVE, JM (2018). “Gentrificación y pauperización de las metrópolis”. Metropolis, n. 07, p. 06. Disponible en: https://www.metropolis.org/sites/default/files/resources/Gentrificacion-pauperizacion-metropolis.pdf

RODE, Phillip (2020). "London and COVID-19: Too complex for one government?” en Agustí Fernández de Losada y Hannah Abdullah (Eds.), "Cities on the frontline: Managing the coronavirus crisis", Barcelona: Barcelona Centre for International Affairs.

ROLNIK, Raquel (2020). Como a densidade das cidades se relaciona com a difusão da pandemia? Junio 25, 2020, de A Cidade É Nossa. Disponible en: https://raquelrolnik.blogosfera.uol.com.br/2020/06/25/como-a-densidade-dascidades-se-relaciona-a-pandemia/

SÁNCHEZ, Daniela (2018). Urbanismo táctico, ¿̇un parche a los problemas de la ciudad?: El juicio de los arquitectos. La Segunda, p. 24.

TODERIAN, Brent (2020). Op-Ed: Dear Gov. Cuomo, The Problem Is Crowding, Not 'Density'! Abril 6, 2020, de Streetsblog NYC. Disponible en: https://nyc.streetsblog.org/2020/04/06/op-ed-dear-gov-cuomo-the-problem-iscrowding-not-density/

VUCHIC, Vukan (1999). Transportation for livable cities. New Brunswick, Center for Urban Policy Research.

WALTERS, Chris (2020). Plan for people of color. Junio 15, 2020, de Association for Neightborhood \& Housing Development. Disponible en: https://anhd.org/blog/plan-for-people-of-color

ZEVI, Andrea Tobia (2020). "First in the western world. Milan goes from boom-town to emergency hot-spot" en Agustí Fernández de Losada y Hannah Abdullah (Eds.), "Cities on the frontline: Managing the coronavirus crisis", Barcelona: Barcelona Centre for International Affairs. 